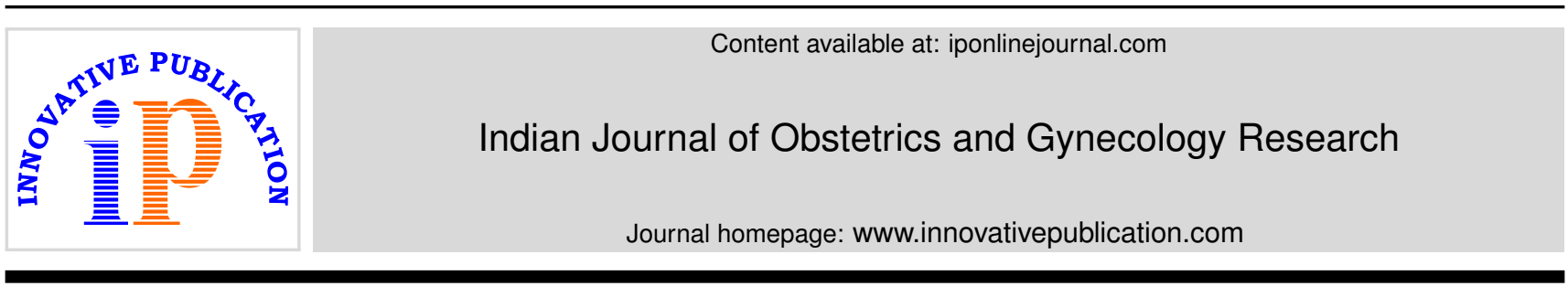

Original Research Article

\title{
Seasonal variations in the incidence of preeclampsia-eclampsia in Bayelsa state in the Niger Delta Region of Nigeria
}

\author{
Ikeanyi M Eugene ${ }^{1, *}$, Abasi J Isaac ${ }^{1}$ \\ ${ }^{1}$ Dept. of Obstetrics and Gynaecology, Niger Delta University Teaching Hospital, Bayelsa, Nigeria
}

\section{A R T I C L E I N F O}

\section{Article history:}

Received 08-05-2020

Accepted 14-05-2020

Available online 15-06-2020

\section{Keywords:}

Preeclampsia

Eclampsia

Seasonal

Variation

Incidence

Wet

Dry

\begin{abstract}
A B S T R A C T
Background: Preeclampsia is one of the leading causes of fetal and maternal morbidity and mortality mostly in the less developed settings. It is a common confounding disorder of pregnancy complicating $3-10 \%$ of pregnancies worldwide. Its pattern and etiology are still very unclear.

Objective: To investigate the influence of the seasonal variations as defined by atmospheric temperature, air relative humidity and mean rainfall on the incidence of preeclampsia-eclampsia.

Materials and Methods: This was a case series observational study that took place in a tertiary hospital between 2012 and 2019. Analyzed data was extracted from the hospital admission and discharge records of the preeclampsia-eclampsia women who delivered at the study center in the study period. Meteorological variables were atmospheric temperature, relative humidity and rainfall. The season was stratified into the wet humid season (April-October) and the dry hot season (November-March) based on these weather parameters. The seasons and the months were independent variables while the incidence of preeclampsia was the dependent variable.

Results: From our data the incidence of preeclampsia-eclampsia was $7.2 \%$. The mean values were $6.7 \%$ and $7.9 \%$ for wet and dry seasons respectively. The incidence of preeclampsia-eclampsia was on the increase over the years of this data. The monthly peak incidences in each year within the study period were consistently recorded in the months of February, August and December respectively.

Conclusions: The rate of occurrence of preeclampsia-eclampsia appeared to vary with the seasons. The incidence appeared to be higher in the dry season with peaks at inter-seasonal periods.
\end{abstract}

(C) 2020 Published by Innovative Publication. This is an open access article under the CC BY-NC license (https://creativecommons.org/licenses/by-nc/4.0/)

\section{Introduction}

Preeclampsia contributes substantially to maternal and perinatal morbidity and deaths globally, yet its etiology is still largely unclear and its pathophysiology still evolving. Its etiology is surrounded by many theories yet none is conclusive. The disorder can progress in a spectrum; from non-proteinuric hypertension in pregnancy through preeclampsia to eclampsia.

Recently, there has been an accumulating evidence suggesting the likelihood of seasonal influence on the occurrence of preeclampsia-eclampsia. ${ }^{1-3}$ Climatic variation has been variously linked to the pattern of preeclampsia-

\footnotetext{
* Corresponding author.

E-mail address: abuchikeanyi@yahoo.com (I. M. Eugene).
}

eclampsia globally. Some studies have associated increased incidence of preeclampsia with wet humid periods in tropical and winter in non-tropical climates ${ }^{4-6}$ while others found no association ${ }^{7}$ and yet others reported increased incidence in summer; hot atmospheric temperature and low humidity season. ${ }^{8-12}$ The literature tends to associate occurrence of eclampsia, and possibly the trigger of seizure in the presence of preeclampsia with low atmospheric temperature and barometric pressure, high humidity and rainfall. $^{7}$

Bayelsa state; the study area is in the heavy rainfall zone with the attendant high humidity and low temperature in the core Niger Delta region of the south-south geopolitical zone of Nigeria. Her climate is tropical with significant rainfall most of the months, a short dry season, mean annual rainfall 
of $2899 \mathrm{~mm}$ and a mean annual temperature $26.7^{\circ} \mathrm{C} .{ }^{13}$

The driest month in the study setting is January with a mean rainfall of $40 \mathrm{~mm}$ while the greatest precipitation is in September with $472 \mathrm{~mm}$. The warmest month is March with a mean temperature of $28^{\circ} \mathrm{C}$ while the lowest temperature is in July $25.4^{\circ} \mathrm{C}$. The difference of precipitation is $432 \mathrm{~mm}$ between the wettest and driest months and temperature variation throughout the year is $2.6^{\circ} \mathrm{C} .{ }^{13}$ The wet season is warm and overcast, and the dry season hot and cloudy in the region.

If knowledgeable anticipation and adequate preparedness are put in place, the high morbidity and mortality from preeclampsia-eclampsia will be substantially mitigated by quality planning of pregnancy with conscious anticipation, early and aggressive interventions. This study was therefore conducted to investigate the seasonal variation of preeclampsia-eclampsia in the Niger Delta region of Nigeria in the West Africa sub-region.

\section{Materials and Methods}

This case series study took place at Niger Delta University Teaching Hospital (NDUTH). Niger Delta University Teaching Hospital is a tertiary health institution domicile in Bayelsa state; one of the coastal states in the Niger Delta region of Nigeria. Bayelsa State is bordered to the east by Rivers State, to the west and south by the Atlantic Ocean and to the north by Delta State. It covers $10,773 \mathrm{~km}$ and geographically situated within latitude $4^{\circ} 15^{\prime \prime}$ north and latitude $5^{\circ} 23^{\prime \prime}$ south and within longitudes $5^{\circ} 22^{\prime \prime}$ West and $6^{\circ} 45^{\prime \prime}$ East. The setting is characterized by almost all year rainfall with an average of $2000-4000 \mathrm{~mm}$ rainfall. The mean monthly temperature range is $25^{\circ} \mathrm{C}-31^{\circ} \mathrm{C}$ while the mean maximum monthly temperature range is $26^{\circ} \mathrm{C}$ to $31^{\circ} \mathrm{C}$ and the mean annual temperature remains uniform in the entire state. The hottest months are December to April, the difference in temperature between wet and dry season is small; about $2^{\circ} \mathrm{C}$ at the most. Basically the climate is tropical in Bayelsa state; wet and dry seasons. This manifests as two; a long and a shorter rainfall maxima interspaced by two; a shorter and a longer dry seasons. The first rainy season is from March to July with the peak in June. This is then interrupted by a short period of about two to three weeks in August with minimal or no rain fall termed 'August break' by the locals. This is followed by a shorter rainy season from early September to November with peak in October (Figure 1). This is then followed by the dry season from December to February a maximum mean daily temperature of about $33^{\circ} \mathrm{C}$. The highest and the lowest mean daily temperatures coincide with the dry season and rainfall maxima respectively. Relative humidity is high all through the year with a slight decrease in the dry seasons. For the purpose of this study, however, the seasons will be divided into two; a dry season (November, December, January, February and March) and a wet season (April-July,
August, September and October). The month of August is more a dry and less a wet period in the setting as earlier stated but was included in the wet season in this study as that 'dry' period within August is relatively very short, and is not seen as a 'season'.

The population of Bayelsa state is over two million and is made up mostly of the indigenous Ijaw, Nembe, Ogbia, Epie - Atissa and residents from the neighboring states and across Nigeria and other nationals. Farming, fishing and trading are the leading indigenous occupations. Oil and gas prospecting companies are common in the region.

Data were collected on the cases of preeclampsiaeclampsia that were managed at the study center within the study period January 2012 to December 2019 using the labor ward and theater records and patient files to extract the relevant data. Literatures on the Meteorology of Bayelsa state were reviewed for the relevant climatic data. ${ }^{13}$ Recruitment was with the aid of a designed questionnaire using non probability sampling method.

The data was fed into the Epi Info statistical package. Only the cases of proteinuric hypertension (BP $\geq 140 / 90 \mathrm{mmhg}$ ) in the second half of gestation in previously normotensive non proteinuric women were purposively included. Those with this background even without proteinuria and who had no known neurological disorder that fitted were taken as eclamptic and were included. All cases of pregestational hypertensive diseases, non-proteinuric hypertension in pregnancy and multiple pregnancy were excluded. Data on selected sociodemographic characteristics of participants, year and month of delivery were fed into the Epi Info spreadsheet. Each month incidence of preeclampsia-eclampsia was calculated per hundred deliveries and the mean incidence for each set of the months over the study period to compare the monthly variations. The process of data collection did not involve subject identifiers therefore did not require individual subject consent. This was a retrospective study with minimal risk and the institutional Research and Ethical Committee approval therefore, was not sought.

The mean seasonal incidences for the wet and the dry seasons were calculated and compared using Student-ttest. Chi-square test was used for necessary comparative statistics. Statistical significance was set at $\mathrm{p}<.05$ and $95 \%$ Confidence interval exclusion of nullity of one.

This study appraised the seasonal variation of preeclampsia-eclampsia. For the purpose of this study the seasonal variation was limited to only the values of air temperature, precipitation and humidity (the concentration of water vapor in atmospheric air) of the air to define the seasons.

\section{Results}

There were 259 preeclampsia-eclampsia cases among 3619 deliveries that took place within the study period; a 


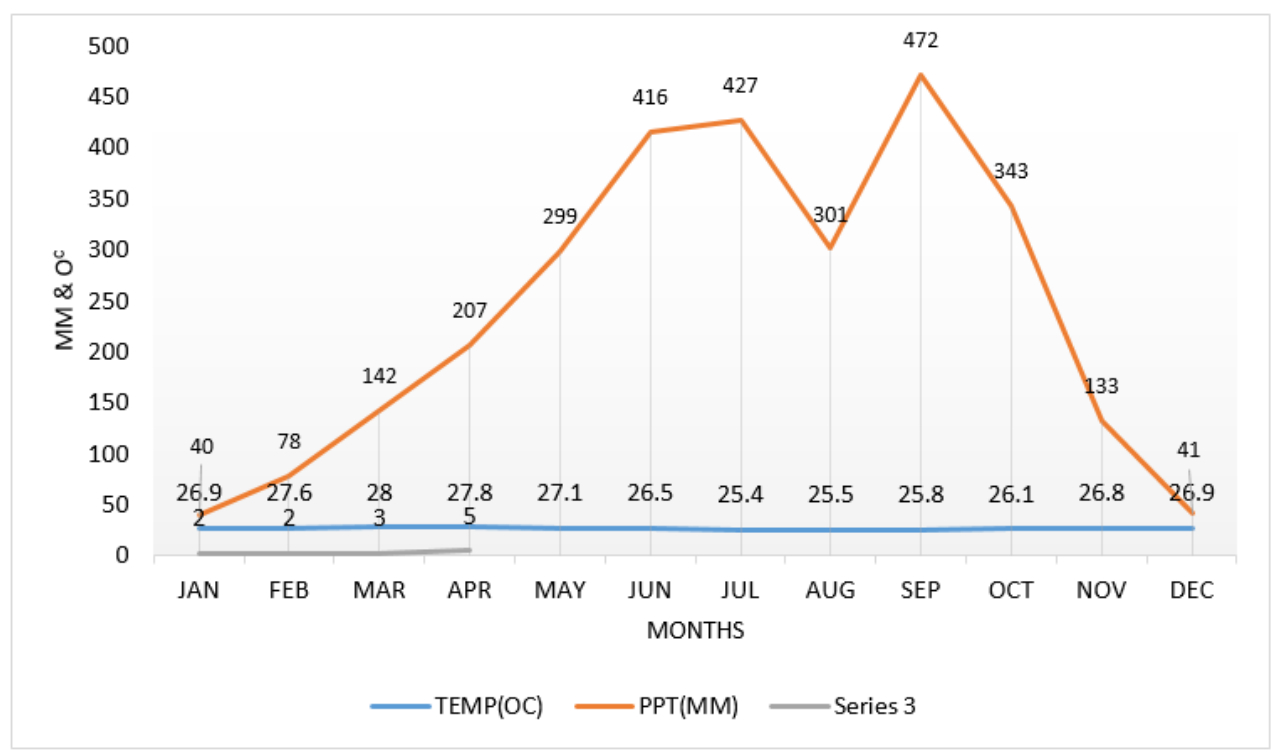

Fig. 1: Monthly precipitation and temperature of the study region

preeclampsia-eclampsia incidence of $7.2 \%$. About three out of every ten participants were 35 years of age or older while $22(8.3 \%)$ were younger than twenty years old. Approximately two of every five $(38.0 \%)$ of them were nulliparous and of tertiary level of education. Three of every five of them were indigenous Ijaw people.

Figure 2 is the display of the yearly occurrence of preeclampsia-eclampsia over the study period. The trend is upward with an almost alternate rise and fall pattern with a baseline increase over the study period. The highest incidences were recorded in 2014 and 2019 with the lowest in the first two years of the study.

Figure 3 shows monthly preeclampsia-eclampsia incidence of each year for the period of the study. The breaks in the line graphs were periods that services were not provided at the study center either because of flooding or staff strike; thus for 2014 (gray color, December) and 2016 (blue, JuneJuly). The peak monthly incidences in most of the years were recorded in February, August and December and less rise in May-June

The dips in incidence were recorded in the months of January, April and July respectively.

Figure 4 is a display of the mean monthly incidences of preeclampsia-eclampsia. Generally, there was an upward slope in the trend from the beginning to the end of the year. The highest mean monthly incidence of preeclampsiaeclampsia occurred in months of February, August and December. The lowest values were in January, April and July. A total of 149 preeclampsia-eclampsia cases were managed among 2222 mothers who delivered in the wet seasons from April to October each year for the study period ;an incidence of $6.7 \%$ while $110 / 1397$ took place in the dry seasons between November and March each year for the same period; an incidence of $7.9 \%$ in the dry seasons. The difference was not statistically significant $(\mathrm{OR}=0.84$, $\mathrm{p}=0.21$ ).

\section{Discussion}

The overall incidence of preeclampsia-eclampsia from this data was $7.2 \%$ and this was lower than a report from Kinshasa, Democratic Republic of Congo(DRC), ${ }^{10}$ but higher than another from Khorramabad city Iran. ${ }^{8}$ The incidence was higher at $7.9 \%$ in the dry season than $6.7 \%$ in the wet season and this was consistent with reports by other researchers. ${ }^{8,14,15}$ Higher rate of preeclampsia was reported during the dry season in Kinshasa DRC. ${ }^{10}$ The researchers opined that Low temperature can be viewed as an aggravating factor instead of a cause of preeclampsia. Similarly Jamelle reported a significant rise in the incidence of eclampsia in the hot summer period of the months of May to September with a daily atmospheric temperature range of $30-35^{\circ} \mathrm{Cin}$ Rawalpindi Punjab province, Pakistan that became stables in the rest of the year including winter. ${ }^{16} \mathrm{He}$ however, noted either non-significant variation in eclampsia in some regions outside Punjab or significant rise during the cold winter season in some other parts of the country. ${ }^{16}$ Wacker et al. reported peak incidence of preeclampsia at the end of the dry season in two district hospitals and a small number of cases of eclampsia in months with no or low rainfall. ${ }^{17}$ Other researchers reported increased risk of pre-eclampsia among women who conceived in summer and had a long exposure to higher ambient temperature. ${ }^{18}$

The incidence from our data was higher in the dry high temperature, low precipitation and humidity season. This is the period characterized in the study area by high 
Table 1: Characteristics of Participants $n=259$

\begin{tabular}{lccc}
\hline Characteristic & Variable & Frequency & \% \\
Maternal age & $<35$ & 182 & 70.3 \\
& $\geq 35$ & 77 & 29.7 \\
Parity & $\geq 1$ & 98 & 38 \\
& $\leq 2^{o}$ & 161 & 62 \\
Education & $>2^{o}$ & 162 & 62. \\
Ethnicity & I jaw & 155 & 37.5 \\
& Others & 104 & 59.8 \\
\end{tabular}

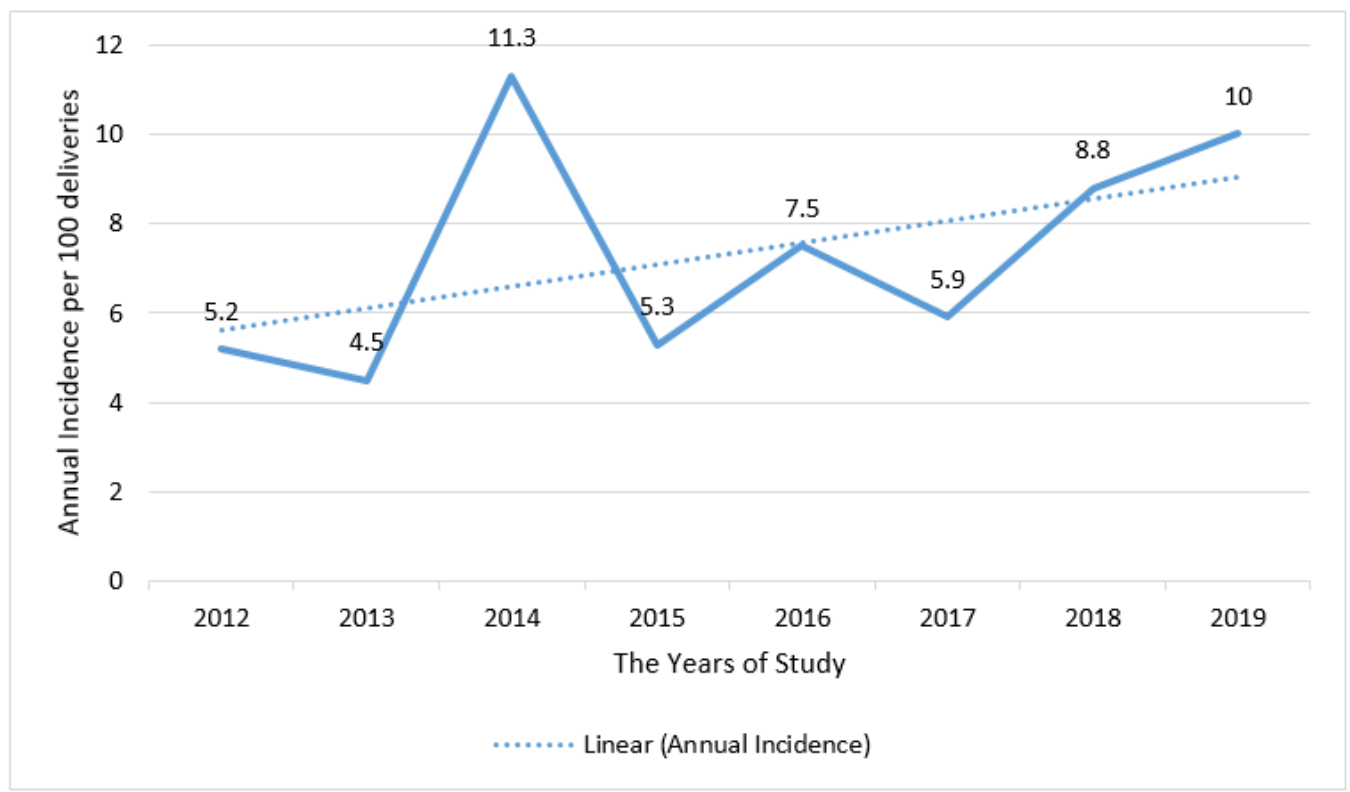

Fig. 2: Annual incidence of pre-eclampsia 2012-2019

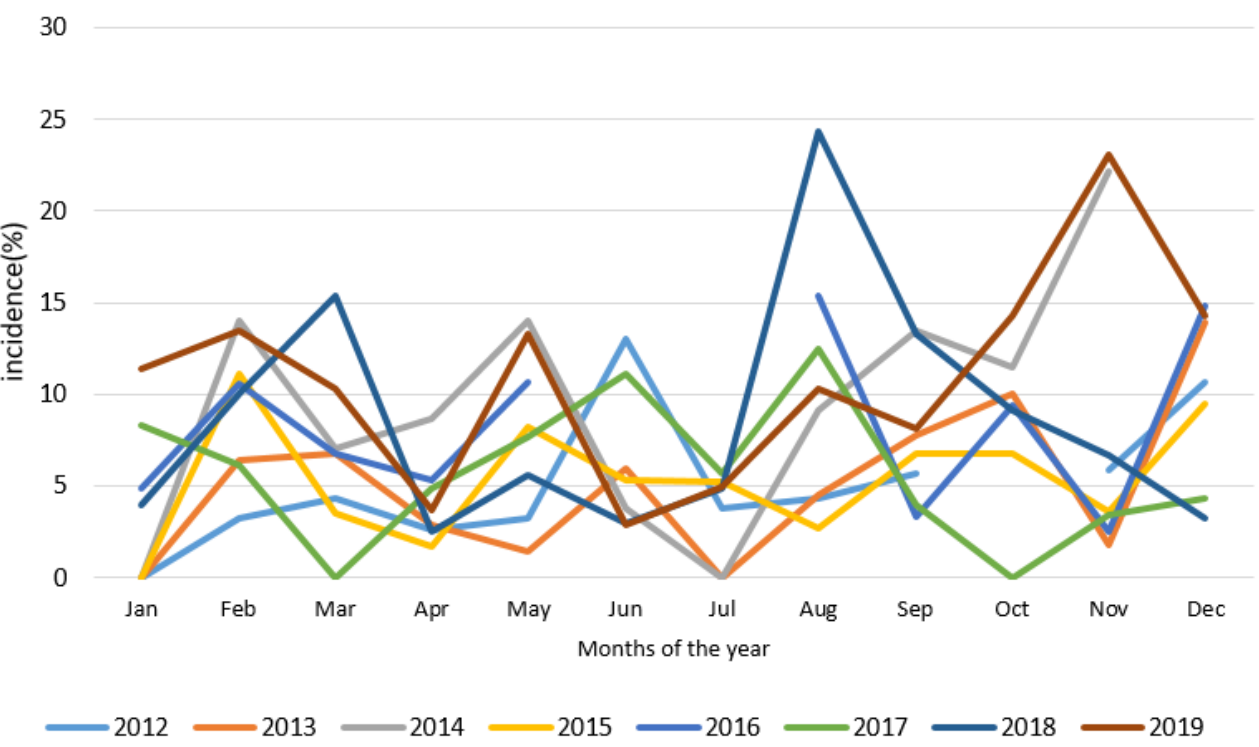

Fig. 3: Monthly incidence of preeclampsia-eclampsia 


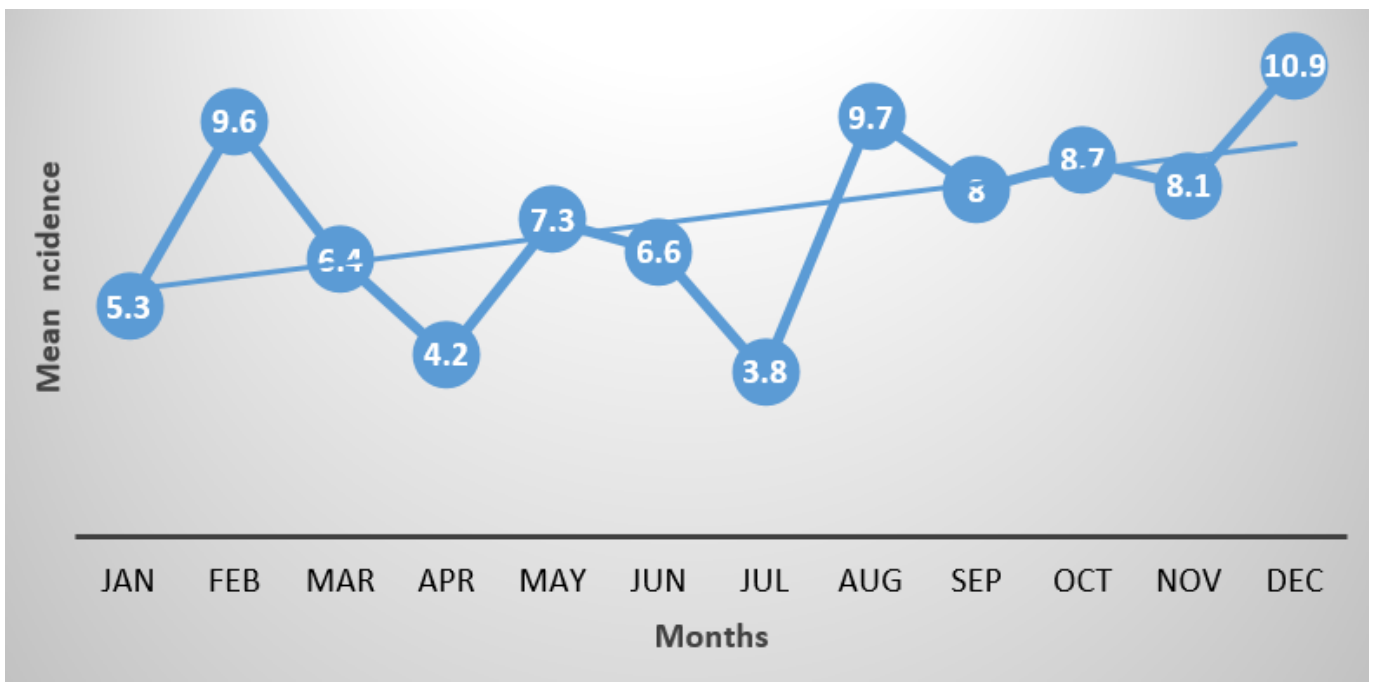

Fig. 4: Mean monthly incidence of preeclampsia-eclampsia over the period of study

perspiration, hemoconcentration, hemoviscosity, high rate of human mosquito biting. Our result was in contrast to those of other researchers reporting higher incidence of the disorder in deliveries during the wet season. ${ }^{4}$ Among the reasons given by these workers for the relatively increased incidence of gestational hypertension, preeclampsia and eclampsia in wet humid season were seasonal variation in infectious diseases, malaria, environmental triggers of asthma, vitamin D levels, physiological responses to cold temperatures, healthcare access, nutritional intake and unknown factors. ${ }^{3,4,19}$

From our study, the months of February, August and December almost consistently had the leading incidences of preeclampsia-eclampsia in each of the years of the study period. These months appear to coincide with the time of the transition from dry season to rainy wet season or the other way round. February-March is a transition period from the dry to the wet rainy season in the study region. August in the study region is characterized by the transition from wet season to the short dry period ('August break') of about two to three weeks within the wet rainy season with subsequent return to the wet rainy period towards its end or early in September. Likewise, the months of NovemberDecember coincide with the change to the dry season. The months of stable weather (compared to the transition months as above), in either wet or dry season recorded lower incidences of preeclampsia-eclampsia. The peaks of rainy season or dry season each did not record substantial change in the incidence of preeclampsia-eclampsia. The earth's tilt on its axis and variation of the amount of the sunlight to any point on earth as the earth constantly revolves round the sun brings about the variations and the elements of the seasons including the atmospheric temperature, precipitations, atmospheric pressure and humidity etc. The human system is expected to variably respond or react to the resultant variations in these elements of the season as they vary. An important attribute of human as other living things is responsiveness or irritability, recovery and adaptability to her environmental changes. This may offer some explanation to the relative stable incidences observed as either season stabilized in this data while the response to the switch of the seasons with a rise in occurrence of hypertensive disorders of pregnancy seems a possibility. Another possible explanation for the increased risk of preeclampsia-eclampsia in the dry season can be attributed to the trigger of the hypothalamo- posterior pituitary axis to release antidiuretic hormone (ADH)/vasopressin in the dry season to maintain fluid homeostasis. This results in increased retention of salt and water and consequent rise in blood pressure in labile persons. Various other conflicting postulations have been put forward by many workers to try to explain the variation of pre-eclampsiaeclampsia incidence with seasonal variations. Workers in Harare Zimbabwe, implicated the lack of vitamins, minerals or other important nutrients during the last weeks of the dry season as the possible trigger of pre-eclampsia. ${ }^{17}$ This was corroborated by Elongi et al. working in Kinshasa, who argued that pre-eclampsia often develops in dry season just before the rainy season, and is likely tied to a shortage of food. ${ }^{10}$ just as opined by another researcher. ${ }^{20}$ The Kinshasa DRC researchers opined that Low temperature can be viewed as an aggravating factor instead of a cause of preeclampsia. ${ }^{10}$ They felt that agriculture; nutritional inadequacy may be a potential etiology and recommended studies on the effect of nutritional deficiencies on eclampsia.

Wacker et al. associated the peak eclampsia incidence in the dry season to lack of vitamins and minerals that may occur in last weeks of the dry season and thereby trigger preeclampsia. ${ }^{17}$ To further corroborate our finding of increased incidence of preeclampsia-eclampsia in the 
dry season, was a report ascribing protective effect of diets of vegetables, fruits, vegetable oil, plant foods against preeclampsia. ${ }^{21}$ and these foods are largely seasonal, mostly available and much more widely consumed in the wet farming season, in our study setting. On the contrary however, the same study also reported increased risk of preeclampsia with a diet pattern high in processed meat, salty snacks and sweet drinks. ${ }^{21}$ These foods are consumed more in the study setting in the times of scarcity of plant foods.

\section{Source of Funding}

None.

\section{Conflict of Interest}

None.

\section{References}

1. Khojasteh F, Safarzadeh A, Borayri T, Baghban K. Survey correlation between preeclampsia and season and some of its risk factor in pregnant women. Jf Women's Health Care. 2012;01(03):79-84.

2. Magnus P, Eskild A. Seasonal variation in the occurrence of preeclampsia. BJOG. 2001;108(11):116-9.

3. Okafor UV, Ezegwui HU. Cesarean delivery in preeclampsia and seasonal variation in a tropical rainforest belt. J Postgrad Med. 2010;56(1):21. Available from: https://dx.do1.org/10.4103/0022385062431

4. Tepoel MR, Saftlas AF, Wallis AB. Association of seasonality with hypertension in pregnancy: a systematic review. J Reprod Immunol 2011;89(2):140-52.

5. Wellington K, Mulla ZD. Seasonal Trend in the Occurrence of Preeclampsia and Eclampsia in Texas. Am J Hypertens. 2012;25(1):115-9.

6. Morikawa M, Yamada T, Yamada T, Cho K, Sato S, Minakami H. Seasonal variation in the prevalence of pregnancy-induced hypertension in Japanese women. J Obstet Gynaecol Res. 2014;40(4):926-31.

7. Subramaniam V. Seasonal variation in the incidence of preeclampsia and eclampsia in tropical climatic conditions. BMC Women's Health. 2007;7(1). 001:0.186/47/2-6874-7-18

8. Janani F, Changaee F. Seasonal variation in the prevalence of preeclampsia . J Family Med Prim Care. 2017;6(4):766-9.

9. Ali AA, Adam GK, Abdallah TM. Seasonal variation and hypertensive disorders of pregnancy in eastern Sudan. J Obstet Gynaecol.
2015;35(2):153-4.

10. Elongi JP, Tandu B, Spitz B, Verdonck F. Influence of the seasonal variation on the prevalence of pre-eclampsia in Kinshasa. Gynecol Obstet Fertil. 2011;39:132-137.

11. Pitakkarnkul S, Phaloprakarn C, Wiriyasirivaj B, Manusirivithaya S, Tangjitgamol S. Seasonal variation in the prevalence of preeclampsia. J Med Assoc Thai. 2011;94:1293-8.

12. Phillips JK, Bernstein IM, Mongeon JA, Badger GJ. Seasonal variation in preeclampsia based on timing of conception. Obstet Gynecol. 1951;104:1015-1020.

13. Yenagoa Bayelsa State Nigeria Climate Meteoblue Climate Diagrams; 2006.

14. Shahgheibi S, Rezaie M, Kamangar TM, Zarea S. Seyedeh Reyhaneh Yousefi, The Effect of Season on the Prevalence of Preeclampsia. J Clin Gynecol Obstet. 2016;5(3):81-4.

15. Hounton SH, Sombie I, Townend J, Ouedraogo T, Meda N, Graham WJ. The tip of the iceberg: Evidence of seasonality in institutional maternal mortality and implications for health resources management in Burkina Faso. Scand J Public Health . 2008;36(3):310-7.

16. Jamelle RN. Eclampsia:is there a seasonal variation? J Obstet Gynaecol. 1998;24(2):121-8.

17. Wacker J, Schulz M, Fruhauf J, Chiwora FM, Solomayer E, Bastert G. Seasonal change in the incidence of preeclampsia in Zimbabwe. Acta Obstet Gynecol Scand. 1998;77:712-6.

18. Tam WH, Sahota DS, Lau TK, Li CY, Fung TY. Seasonal Variation in Pre-eclamptic Rates and its Association with the Ambient Temperature and Humidity in Early Pregnancy. Gynecol Obstet Invest. 2008;66:22-6.

19. Anya SE. Seasonal variation in the risk and causes of maternal death in The Gambia: Malaria appears to be an important factor. Am Soc Trop Med Hyg . 2004;70(5):510-3.

20. Association of anemia, pre-eclampsia and eclampsia with seasonality: A realist systematic review. Health Place. 2015;p. 180-92.

21. Brantsaeter AL, Haugen M, Samuelsen SO, Torjusen H, Trogstad L, Alexander J, et al. A dietary pattern characterized by high intake of vegetables, fruits, and vegetable oils is associated with reduced risk of preeclampsia in nulliparous pregnant norwegian women. J Nutr. 2009;139(6):1162-8.

\section{Author biography}

\section{Ikeanyi M Eugene Consultant}

Abasi J Isaac Consultant

Cite this article: Eugene IM, Isaac AJ. Seasonal variations in the

incidence of preeclampsia-eclampsia in Bayelsa state in the Niger Delta

Region of Nigeria. Indian J Obstet Gynecol Res 2020;7(2):157-162. 